Porous ceramics for multistage Knudsen micropumps—-modeling approach and experimental evaluation

This article has been downloaded from IOPscience. Please scroll down to see the full text article.

2011 J. Micromech. Microeng. 21095029

(http://iopscience.iop.org/0960-1317/21/9/095029)

View the table of contents for this issue, or go to the journal homepage for more

Download details:

IP Address: 141.211.173.82

The article was downloaded on 06/04/2012 at 16:19

Please note that terms and conditions apply. 


\title{
Porous ceramics for multistage Knudsen micropumps-modeling approach and experimental evaluation
}

\author{
Naveen K Gupta and Yogesh B Gianchandani \\ Department of Mechanical Engineering, University of Michigan, 1301 Beal Avenue, Ann Arbor, \\ MI 48109, USA \\ E-mail: gnaveen@umich.edu
}

Received 1 April 2011, in final form 5 June 2011

Published 19 August 2011

Online at stacks.iop.org/JMM/21/095029

\begin{abstract}
This paper describes the evaluation of four types of porous ceramics for use as thermal transpiration materials in Knudsen pumps that operate at atmospheric pressure. Knudsen pumps are motionless gas pumps that utilize thermal transpiration along a channel or a set of channels; the channels must have a temperature gradient and must constrain the flow to remain within the free molecular or transitional flow regimes. Of the ceramics evaluated, a clay-based, 15 bar synthetic ceramic (15PC) presents the most favorable properties for Knudsen pumps. For an input power of $3.4 \mathrm{~W}$, a $25 \times 25 \mathrm{~mm}^{2}$ nine-stage Knudsen pump that uses this material provides a maximum pressure head of $12 \mathrm{kPa}$ and a maximum gas flow rate of $\approx 3.7 \mu \mathrm{L} \mathrm{min}{ }^{-1}$. Reliability tests demonstrate more than $11750 \mathrm{~h}$ of continuous operation without any deterioration in their gas pumping capabilities. A fitted model suggests that the temporal evolution of pressure at the sealed outlet of a Knudsen pump can be captured adequately using four parameters. These parameters correspond to various nonidealities that play dominant roles in the transient response of these pumps.
\end{abstract}

(Some figures in this article are in colour only in the electronic version)

\section{Introduction}

Interest in handheld microsampling and microanalysis systems, such as those for gas analysis, biological assays and cooling, has created a need for more efficient, compact and reliable gas micropumps. Over the years, a variety of mechanisms have been explored for gas micropumps [Las04, Tsa07, Ngu02]. The concepts explored in the past are essentially diaphragm pumps with different actuation mechanisms. These include, for example, electromagnetic [Dar96], electrostatic [Cab01, Kim07], piezoelectric [Ste93, Sch02] and thermo-pneumatic [Sch94] actuation mechanisms. However, various factors, such as structural complexity, reliability, cost and need for undesirably high voltages, have adversely affected widespread adoption. Moreover, these pumping mechanisms are the miniaturized derivatives of macroscale ones, which typically have several moving parts. With miniaturization, the surface area to volume ratio of moving parts increases, resulting in increased frictional losses. It also adversely affects life expectancy and performance.

Thermal molecular pumping can potentially overcome some of these challenges because it does not require any moving parts. Unlike conventional micropumps, thermal molecular pumps [Hob00], which include Knudsen pumps [Knu09], accommodation pumps [Hob70] and thermomolecular pumps [Tra74], exploit the molecular behavior of rarefied gas. Accommodation pumps exploit the difference in the scattering of gas molecules at different types of surfaces [Hob70], whereas thermomolecular pumps exploit the anisotropy in the molecular fluxes resulting from the violation of the cosine reflection law at certain surfaces [Tra74]. Hence, for these two pumps to be functional, it is important to choose the proper type of material with controlled surface conditions. In this effort, the thermal transpirationdriven Knudsen pump is chosen because its performance is less sensitive to the material choice and surface conditions, which can be hard to control precisely. 


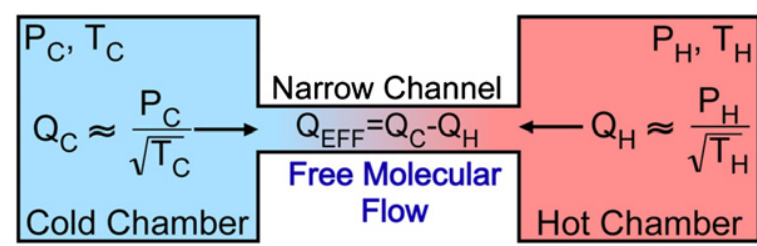

Figure 1. Schematic for thermal transpiration-driven gas flow through a narrow channel connecting two chambers at different temperatures. If the gas flow through the narrow channel is in a free molecular regime, the gas flux from one chamber to another along the narrow channel is ideally proportional to $\mathrm{P} / \sqrt{\mathrm{T}}$. At equilibrium, the molecular flux from the two chambers nullify each other.

Figure 1 illustrates the thermal transpiration-driven gas flow through a narrow channel connecting two isolated chambers at different temperatures $\left(T_{H}\right.$ and $\left.T_{C}\right)$. The narrow channel permits flow only in the free-molecular or transitional flow regimes. A narrow channel has Knudsen number $(K n)$, defined as the ratio of the mean free path of the gas molecules to the hydraulic diameter of the channel, greater than 0.1 [Loe34, Ken38, Kar05]. Ideally, if the gas flow in the narrow channel is in a free molecular regime, the gas flow from one chamber to another is directly proportional to the pressure and inversely proportional to the square root of the temperature of that chamber. In this case, the ratio of the pressure in the two chambers $\left(P_{H}\right.$ and $P_{C}$ ), at equilibrium, is the square root of their absolute temperatures. The phenomenon of thermal transpiration was first analyzed, independently, by Reynolds and Maxwell, who contemporarily proposed rigorous mathematical analyses for the phenomenon in the year 1879 [Rey79, Max79]. In 1909, Knudsen proposed a gas pumping mechanism based on this phenomenon. Since 1909, various researchers have contributed toward the development of the Knudsen pump [Var96, Var01, Mun02, Ale05, Col05, McN05, You05, Ale06, Han07, Han09, Kos08, Guo09, Pha10, Gup11]; however, until recently, the limited options for materials with appropriately narrow channels limited the Knudsen pump operation to sub-atmospheric pressures.

With the recent advances in the microfabrication techniques and with the introduction of materials having submicron-sized capillaries, Knudsen pump operation at atmospheric pressure is possible. One of the earliest reports of Knudsen pumps operating at atmospheric pressure described a membrane with several microchannels for thermal transpiration [Var96]. Subsequently, the same research group reported the use of a mesoporous aerogel, with a pore size of $\approx 20 \mathrm{~nm}$ [Var01]. (Aerogel is a super-critically dried silica gel.) The best case pressure drop was about 11.5 torr with $1.7 \mathrm{~W}$ input power and helium as the working medium. More recently, a 15-stage aerogel-based Knudsen pump, illuminated with $20.9 \mathrm{~mW} \mathrm{~cm} \mathrm{~cm}^{-2}$ of radiant flux, reportedly sustained a steady-state pressure drop of about 120 torr $(\approx 16 \mathrm{kPa})$ [You05]. Another effort utilized lithographically patterned nanochannels in a $1.5 \times 2 \mathrm{~mm}^{2}$ microchip that included a Knudsen pump and capacitive pressure sensors [McN05]. It achieved a pressure drop of about $54.7 \mathrm{kPa}$ with $80 \mathrm{~mW}$ of input power. Although these efforts demonstrate the potential utility of miniature Knudsen pumps, they continue to evolve with respect to throughput, efficiency, size, etc.

Unlike lithographically fabricated surface micromachined nanochannels, porous ceramics have a high density of interconnected micropores, which is necessary to achieve meaningful gas flow rates using Knudsen pumps. Unlike aerogels, ceramics are robust and have high tolerance for moisture and other impurities. We previously introduced the use of a naturally occurring microporous zeolite (clinoptilolite) for transpiration-driven single-stage Knudsen pumping. A single-stage pump provided a limited pressure head of $<1 \mathrm{kPa}$ [Gup08]. ${ }^{1}$ This paper describes the evaluation of four porous ceramics as transpiration materials for atmospheric pressure Knudsen pumps. In particular, the materials evaluated are a porous glass (VYCOR), a naturally occurring zeolite (clinoptilolite) and two clay-based porous ceramics (15 bar porous ceramic and 5 bar porous ceramic). The materials are evaluated by determining the characteristics of singlestage Knudsen pumps (SSKPs) that use these ceramics. The ceramic with the most favorable performance characteristics is used for a multistage Knudsen pump (MSKP). The structure of the device is discussed in section 2 and the modeling strategy in section 3. The experimental results are reported in section 4. Finally, the interpretations of the results are discussed in section 5 .

\section{Device structure}

Figure 2 shows an exploded view of the SSKP. A microporous ceramic disk is bonded peripherally to a thermally insulating polyetherimide (PEI) substrate using a vacuum grade epoxy (STYCAST 2850FT/Catalyst 9). A brass top and a brass base are used to seal the ceramic. The brass base ensures effective thermal contact of the bottom facet of the ceramic to an external heat sink. The upper facet of the ceramic is in thermal contact with a heater through the brass top. The brass top has a cavity for the heater $(\approx 26.5 \Omega)$. The heater (HK5186R25.0L12A, Minco, MN) has a thin, etched-foil resistive element laminated between two insulating layers of Kapton. A PEI cap and a PEI top are used to hold all the components in place and seal the device from above. These elements are bonded to the PEI substrate, which results in two sealed chambersa hot and a cold-on either side of the ceramic disk. This architecture allows the heater to be located outside the hot chamber of the device, which minimizes the possibility of leakage that might otherwise exist at feedthrough locations. Stainless steel capillaries are used to provide inlet and outlet ports from the bottom and the top surfaces of the microporous ceramic, respectively. Conventional machining techniques are used to fabricate the brass and PEI components, while the ceramics are machined using diamond tools. Figure 3 shows the final assembled SSKP; it uses a microporous ceramic disk with a diameter of $\approx 12.75 \mathrm{~mm}$ and a thickness of $\approx 2.75$ $\mathrm{mm}$. The final packaged volume of the SSKP is $18 \times 18 \times$ $6.5 \mathrm{~mm}^{3}$.

1 Portions of this work have been published in conference abstract form in [Gup09]. 


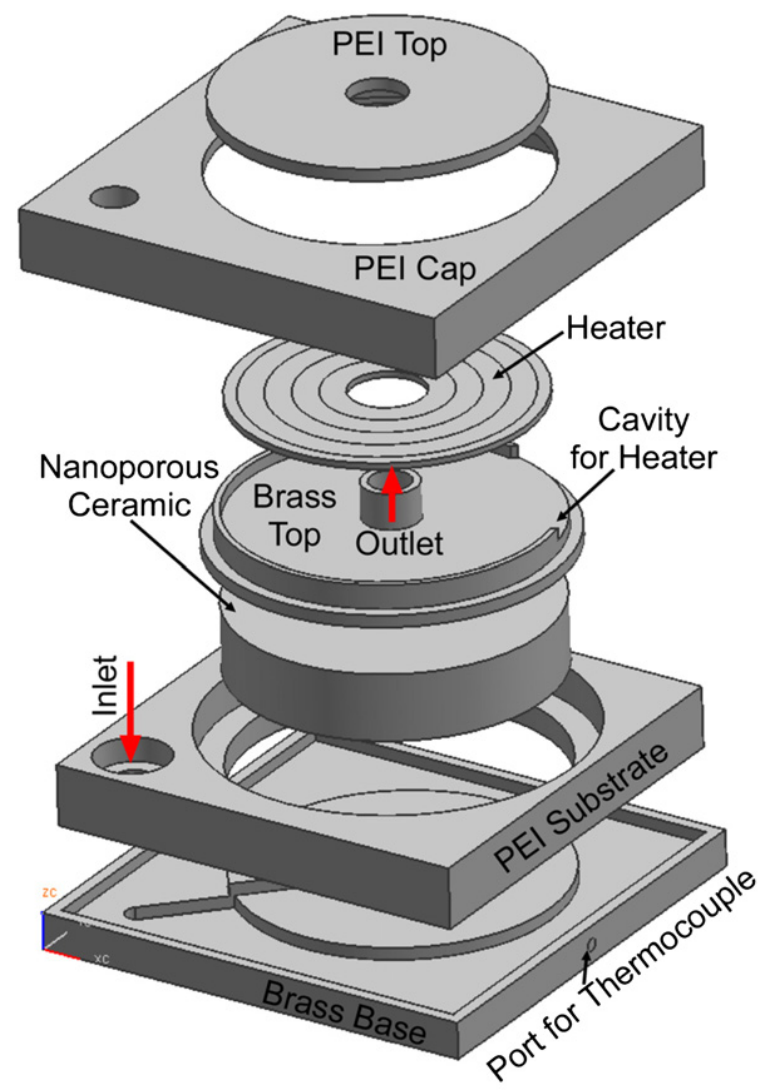

Figure 2. Exploded view of a SSKP showing relative location of various components.

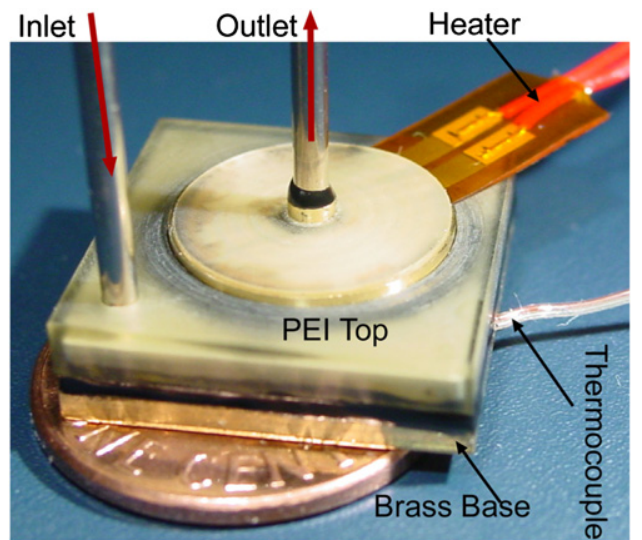

Figure 3. Photograph of the final packaged SSKP. It has a final packaged volume of $18 \times 18 \times 6.5 \mathrm{~mm}^{3}$.

The basic architecture for the MSKP is derived from the SSKP. The nine-stage Knudsen pump has stages arranged in a $3 \times 3$ planar array (figure 4 ). The planar architecture allows a common heater and a common heat sink, which helps with overall thermal efficiency of the device. As in the SSKP, the MSKP also uses a PEI substrate to minimize the parasitic heat losses. The PEI substrate is patterned with nine cavities that house the ceramic disks and nine vertical transfer ports that serve to serially connect the outlet of one stage to the inlet of the next stage. The ceramic disks are bonded peripherally into the cavities in the PEI substrate. Brass caps with embedded

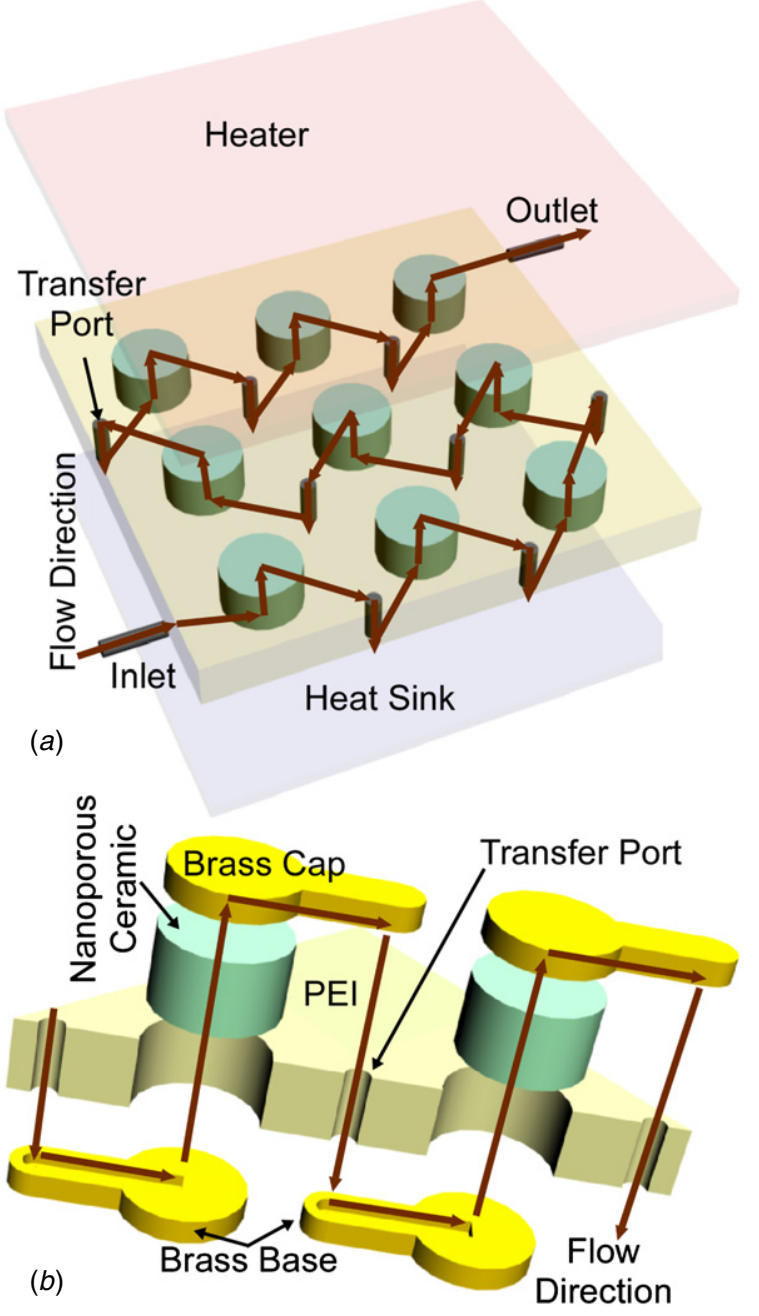

Figure 4. Planar architecture for the MSKP. (a) Planar array of nine SSKPs encapsulated in a polyetherimide substrate. The arrows mark the direction of the flow of the gas molecules from one stage to another. (b) Exploded view of two successive stages of the pump. The arrows show the direction of flow through different elements.

microgroove channels seal each porous ceramic disk from above and below, and direct the gas flow laterally-into or out of each stage through the vertical transfer ports. The caps also provide thermal contact of the ceramic disks with the heater and the heat sink. Figures 5(a)-(c) show various components used in the MSKP. The microporous ceramic disks are $\approx 5 \mathrm{~mm}$ in diameter and $\approx 2.85 \mathrm{~mm}$ thick. The vertical transfer ports are $1 \mathrm{~mm}$ in diameter. The final packaged volume of the MSKP, shown in figure $5(d)$, is $25 \times 25 \times 7.25 \mathrm{~mm}^{3}$.

\section{Modeling strategy}

Several analytical and semi-analytical models for thermal transpiration have been derived from the Boltzmann equation [Cer06]. Of these, Sharipov's model has been identified as one of the most representative models for thermal transpiration in submicron channels [Gup07, Sha74, Sha98]. This model is applicable to a wide range of gas flow regimes. The average 


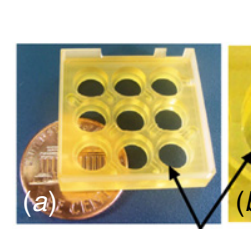

Cavities

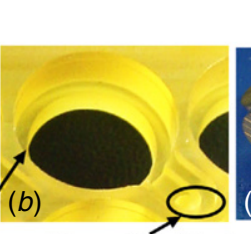

Transfer Port

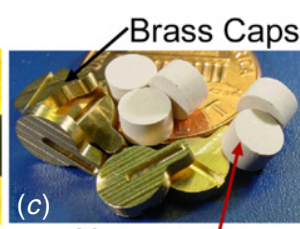

Nanoporous

Ceramics

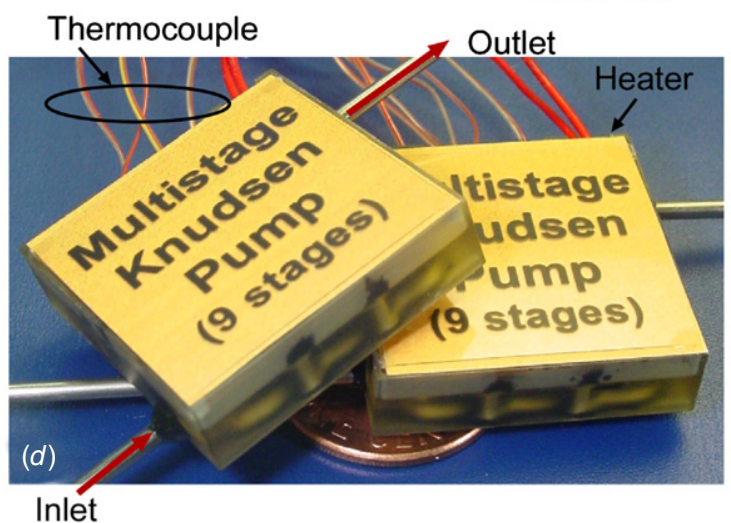

Figure 5. Photographs of various components used in the MSKP and the final packaged MSKP: $(a)$ patterned polyetherimide;

(b) enlarged view of a single cavity; (c) other components used in the pump; and $(d)$ final packaged MSKP with packaged volume of $25 \times 25 \times 7.25 \mathrm{~mm}^{3}$.

thermal transpiration-driven mass flow rate of gas through a narrow circular capillary is [Sha97]

$$
\dot{M}_{\mathrm{TT}}=\left(\frac{Q_{T} \Delta T}{T_{\mathrm{avg}}}-\frac{Q_{P} \Delta P}{P_{\mathrm{avg}}}\right) \frac{\pi a^{3} P_{\mathrm{avg}}}{l}\left(\frac{m}{2 k_{B} T_{\mathrm{avg}}}\right)^{0.5},
$$

where $a$ is the hydraulic radius of the capillary, $l$ is the length of the capillary, $m$ is the mass of the gas molecules, $k_{B}$ is the Boltzmann constant, $Q_{T}$ is the temperature gas flow coefficient, $Q_{P}$ is the pressure gas flow coefficient (table 1) and

$$
\begin{aligned}
& \Delta T=T_{H}-T_{C} ; \quad \Delta P=P_{H}-P_{C} ; \quad T_{\mathrm{avg}}=0.5\left(T_{H}+T_{C}\right) ; \\
& P_{\mathrm{avg}}=0.5\left(P_{H}+P_{C}\right) .
\end{aligned}
$$

Sharipov evaluated $Q_{T}$ and $Q_{P}$ numerically and tabulated their values for a wide range of gas flow regimes [Sha98].

In the viscous regime, i.e. $K n<0.01$, gas flow is described by Poiseuille's equation. The volumetric gas flow rate is

$$
Q_{\mathrm{POS}}=\frac{\pi d^{4}}{128 \mu l} \Delta P,
$$

where $d$ is the hydraulic diameter of a channel that supports Poiseuille's flow and $\mu$ is the dynamic viscosity of gas.

A semi-analytical model was developed to study the temporal evolution of pressure at the sealed outlet (i.e. the hot chamber) of the pumps. The focus was on three physical phenomena: (a) thermal transpiration-driven gas flow across the microporous ceramic; (b) thermal expansion/contraction of air in the hot chamber and (c) leakage between the chambers and to the exterior that is caused by the pressure gradient. The model presented here quantifies various non-idealities in terms of four fitted parameters that are described next.

Analysis suggests that the initial transients in the experimentally measured pressure at the sealed outlet of

\begin{tabular}{|c|c|}
\hline Symbol & Definition \\
\hline$\varepsilon$ & Tolerance limit on the error $e_{\mathrm{RMS}}$ \\
\hline$\varepsilon_{1}$ & Tolerance limit on the error $e_{\mathrm{PHss}}$ \\
\hline$\varepsilon_{2}$ & Tolerance limit on the error $e_{\mathrm{PHin}}$ \\
\hline$\varepsilon_{3}$ & Tolerance limit on the error $e_{\mathrm{PHmx}}$ \\
\hline$\mu$ & Viscosity of gas \\
\hline$\tau_{a}$ & Thermal time constant of the gas in the hot chamber \\
\hline$\tau_{\mathrm{htr}}$ & Thermal time constant of the heater \\
\hline$\Delta P$ & $\begin{array}{l}\left(=P_{H}-P_{C}\right) \text { Pressure differential across the } \\
\text { transpiration element }\end{array}$ \\
\hline$\Delta T$ & $\begin{array}{l}\left(=T_{H}-T_{C}\right) \text { Experimentally measured temperature } \\
\text { bias across the transpiration element }\end{array}$ \\
\hline$a$ & $\begin{array}{l}\text { Hydraulic radius of the nanochannels used for } \\
\text { thermal transpiration }\end{array}$ \\
\hline$a_{\mathrm{TE}}$ & $\begin{array}{l}\text { Unit area of the transpiration element. In this paper } \\
a_{\mathrm{TE}}=1 \mathrm{~cm}^{2}\end{array}$ \\
\hline$d$ & Diameter of a channel \\
\hline$d_{L}$ & $\begin{array}{l}\text { Leak aperture diameter present per unit } \mathrm{cm}^{2} \text { area of a } \\
\text { microporous disk }\end{array}$ \\
\hline$e_{\mathrm{PHin}}$ & $\begin{array}{l}\text { RMS error between the fitted and the experimental } \\
\text { pressure profiles immediately after the heater is } \\
\text { turned on or off }\end{array}$ \\
\hline$e_{\mathrm{PHmx}}$ & $\begin{array}{l}\text { Difference between the maximum pressure values for } \\
\text { the fitted and the experimental pressure profiles }\end{array}$ \\
\hline$e_{\mathrm{PHss}}$ & $\begin{array}{l}\text { Difference between the steady state values of the } \\
\text { fitted and the experimental pressure profiles }\end{array}$ \\
\hline$e_{\mathrm{RMS}}$ & $\begin{array}{l}\text { RMS error between the fitted and the experimental } \\
\text { pressure profiles }\end{array}$ \\
\hline$f$ & $\begin{array}{l}\text { Fraction of experimentally measured temperature } \\
\text { gradient that actually appears across the microporous } \\
\text { ceramic }\end{array}$ \\
\hline$f_{\text {air }}$ & $\begin{array}{l}\text { Ratio of the thermal time constant for air } \tau_{a} \text { to the } \\
\text { thermal time constant of the heater } \tau_{\mathrm{htr}}\end{array}$ \\
\hline$f_{P}$ & Bulk porosity of porous ceramics \\
\hline$k_{B}$ & Boltzmann constant \\
\hline$l$ & $\begin{array}{l}\text { Length of the nanochannels; or thickness of the } \\
\text { microporous ceramic }\end{array}$ \\
\hline$m$ & Mass of a gas molecule \\
\hline$A_{\mathrm{TE}}$ & Area of the transpiration element \\
\hline$D_{L}$ & $\begin{array}{l}\text { Diameter of the leak aperture present in a bulk } \\
\text { microporous material used for thermal transpiration }\end{array}$ \\
\hline$D_{\mathrm{NP}}$ & $(=2 a)$ Hydraulic diameter of the nanochannels \\
\hline Kn & Knudsen number \\
\hline $\begin{array}{l}\dot{M}_{\mathrm{TT}} \\
P_{\text {avg }}\end{array}$ & $\begin{array}{l}\text { Thermal transpiration-driven mass flow rate } \\
\left(=0.5\left(P_{H}+P_{C}\right)\right) \text { Average pressure across the } \\
\text { transpiration element }\end{array}$ \\
\hline$P_{C}$ & Pressure in the cold chamber \\
\hline$P_{\mathrm{Ce}}(t)$ & $\begin{array}{l}\text { Experimentally measured pressure in the cold } \\
\text { chamber at time } t\end{array}$ \\
\hline$P_{\mathrm{Cm}}(t)$ & $\begin{array}{l}\text { Modeled pressure in the cold chamber of the } \\
\text { Knudsen pump at time } t\end{array}$ \\
\hline$P_{H}$ & Pressure in the hot chamber \\
\hline$P_{\mathrm{He}}(t)$ & $\begin{array}{l}\text { Experimentally measured pressure in the hot } \\
\text { chamber at time } t\end{array}$ \\
\hline$P_{\mathrm{Hm}}(\mathrm{t})$ & Modeled pressure in the hot chamber at time $t$ \\
\hline$P_{\mathrm{mxE}}$ & $\begin{array}{l}\text { Experimentally measured maximum pressure head } \\
\text { generated by a SSKP }\end{array}$ \\
\hline$P_{\mathrm{mxM}}$ & $\begin{array}{l}\text { Modeled maximum pressure head that a SSKP can } \\
\text { generate for a given set of structural parameters } a, f_{P} \text {, } \\
\text { and } D_{L}\end{array}$ \\
\hline$Q_{\mathrm{mxE}}$ & $\begin{array}{l}\text { Extrapolated gas flow rate generated by a single stage } \\
\text { Knudsen pump against zero pressure head based on } \\
\text { the experimentally measured load-flow } \\
\text { characteristics of the pump }\end{array}$ \\
\hline
\end{tabular}

Table 1. Nomenclature for the terms/symbols used in this paper. All these terms are assumed to have SI units, unless otherwise specified. 
Table 1. Continued.

\begin{tabular}{|c|c|}
\hline Symbol & Definition \\
\hline$Q_{\mathrm{mxM}}$ & $\begin{array}{l}\text { Modeled maximum gas flow rate generated by a } \\
\text { SSKP against zero pressure head for a given set of } \\
\text { structural parameters } a, f_{P} \text { and } D_{L}\end{array}$ \\
\hline$Q_{P}$ & Pressure gas flow coefficients \\
\hline$Q_{\mathrm{POS}}$ & (Volumetric) Poiseuille flow \\
\hline$Q_{T}$ & Temperature gas flow coefficients \\
\hline$T_{\mathrm{amb}}$ & Ambient temperature \\
\hline$T_{\text {avg }}$ & $\begin{array}{l}\left(=0.5\left(T_{H}+T_{C}\right)\right) \text { Average temperature across the } \\
\text { transpiration element }\end{array}$ \\
\hline$T_{C}$ & $\begin{array}{l}\text { Temperature of the gas molecules enclosed in the } \\
\text { cold chamber }\end{array}$ \\
\hline$T_{\mathrm{Ce}}(t)$ & $\begin{array}{l}\text { Experimentally measured temperature at the cold } \\
\text { side of the ceramic at time } t\end{array}$ \\
\hline$T_{\mathrm{Cm}}(t)$ & $\begin{array}{l}\text { Modeled temperature at the cold facet of the ceramic } \\
\text { at time } t\end{array}$ \\
\hline$T_{H}$ & $\begin{array}{l}\text { Temperature of the gas molecules enclosed in the hot } \\
\text { chamber }\end{array}$ \\
\hline$T_{\mathrm{Ha}}(t)$ & $\begin{array}{l}\text { Modeled temperature of the air enclosed in the hot } \\
\text { chamber at time } t\end{array}$ \\
\hline$T_{\mathrm{He}}(t)$ & $\begin{array}{l}\text { Experimentally measured temperature on the hot side } \\
\text { of the ceramic at time } t\end{array}$ \\
\hline$T_{\mathrm{Hm}}(t)$ & $\begin{array}{l}\text { Modeled temperature at the hot facet of the ceramic } \\
\text { at time } t\end{array}$ \\
\hline$T_{\text {in }}$ & $\begin{array}{l}\text { Initial temperature of the heater measured } \\
\text { experimentally }\end{array}$ \\
\hline$V_{\mathrm{crr}}$ & Corrected volume for the hot chamber \\
\hline
\end{tabular}

a Knudsen pump, which occur as soon as the heater is turned on or off, depend strongly on the rate of thermal expansion/contraction of air within the hot chamber. The experimentally measured temperature of the heater, $T_{\mathrm{He}}$, is used to estimate its thermal time constant, $\tau_{\mathrm{htr}}$. (The exponential transients that are observed are characteristic of conduction-dominated heat transport.) A fitted parameter, $\tau_{a}$, is used for the thermal time constant of the air entrapped in the hot chamber, such that

$$
\tau_{a}=f_{\text {air }} \cdot \tau_{\mathrm{htr}},
$$

where $f_{\text {air }}$ is a scaling factor. This factor should be smaller than 1 because the rate of increase in the temperature of air inside the hot chamber is expected to be smaller than the rate of increase in the temperature of the heater.

A second fitted parameter, the leak aperture diameter, $D_{L}$, is used to model the pressure-driven leakage flow across the ceramic. A typical porous ceramic has grain boundaries and structural imperfections that may have hydraulic diameter significantly greater than the mean free path of the gas molecules (i.e. $K n<0.01$ ) [Kar05]. Some of these imperfections may result from the choice of manufacturing techniques. The gas flow through these imperfections is likely to be in the viscous regime, counteracting the thermal transpiration-driven gas pumping through the micropores. For a given microporous material, $D_{L}$ may vary from device to device because, in addition to the crystal imperfections, it also accounts for the leakage flow across the packaging layers, etc. The leakage flow across the ceramic per unit area $\left(\right.$ in $\left.\mathrm{cm}^{2}\right)$ is represented by the leak aperture diameter, $d_{L}$ :

$$
\frac{d_{L}}{D_{L}}=\left(\frac{a_{\mathrm{TE}}}{A_{\mathrm{TE}}}\right)^{0.25},
$$

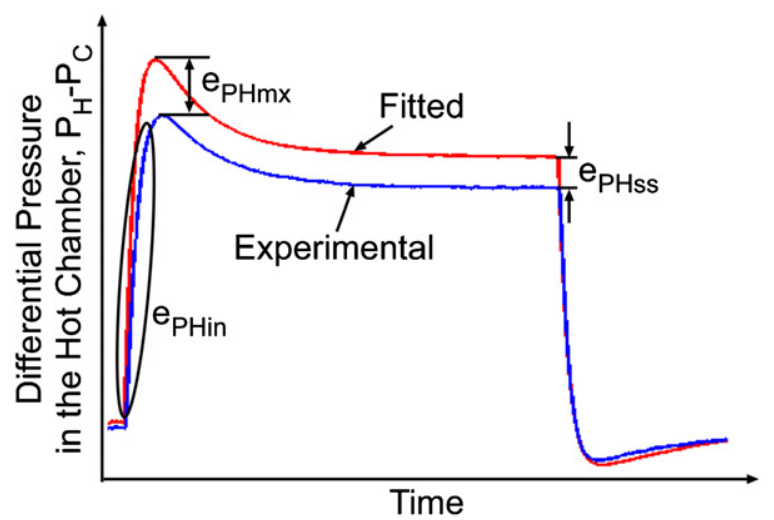

Figure 6. Typical variation in the estimated (i.e. fitted) and the experimentally measured temporal evolution of pressure rise at the sealed outlet of a Knudsen pump.

where $a_{\mathrm{TE}}=1 \mathrm{~cm}^{2}, A_{\mathrm{TE}}$ is the area of the thermal transpiration element in $\mathrm{cm}^{2}$ and $D_{L}$ is the effective leak aperture diameter present in the area $A_{\mathrm{TE}}$ of the transpiration element.

A third fitted parameter, $f$, represents the fraction of experimentally measured temperature bias that actually appears across the microporous ceramic. This parameter accounts for the loss in temperature bias due to asperities and roughnesses at the structural interfaces by a thermal contact resistance at the top facet of the ceramic disk. All other interfaces are assumed to have no thermal contact resistance. Note that because the top facet of the ceramic element is in (indirect) physical contact with the heater through the brass top, it is assumed to share the thermal time constant, $\tau_{\mathrm{htr}}$.

Finally, a fourth fitted parameter, $V_{\text {crr }}$, represents the corrected volume of the hot chamber and is used to account for non-uniformity in temperature of air molecules in the hot chamber. The gas molecules in the vicinity of the heater are significantly hotter than those that are further away. This nonuniformity is modeled by dividing the gas molecules into two sets, each at a different but uniform temperature. The steadystate temperature of the first set of gas molecules, close to the heater, is assumed to be equal to that of the hot facet of the microporous ceramic; the second set of gas molecules is assumed to be at room temperature $T_{\mathrm{amb}}$. The volume occupied by the first set of gas molecules at room temperature and pressure is assumed to be $V_{\text {crr }}$. For the purpose of the model presented here, the corrected volume is treated as the actual volume of the hot chamber. The air encapsulated in this volume is assumed to heat up or cool down with the top facet of the ceramic, but with a longer time constant $\tau_{a}$.

Figure 6 shows the typical variation in the estimated (i.e. fitted) and the experimentally measured transient pressures at the sealed outlet of a Knudsen pump. The deviation of the fitted pressure response from the experimental pressure response is parameterized by three error terms $\left(e_{\mathrm{PHss}}, e_{\mathrm{PHin}}\right.$, $e_{\mathrm{PHmx}}$ ), in addition to $e_{\mathrm{RMS}}$ (figure 6). A step-by-step procedure is used to determine the four fitted parameters such that the root mean square (RMS) error, $e_{\mathrm{RMS}}$, between the estimated and the experimentally measured transient pressure rise at the sealed outlet of a pump is minimized. 
(1) The difference between the steady-state values of the experimental and the fitted pressure responses, indicated by $e_{\mathrm{PHs}}$ in figure 6 , has been observed to depend primarily on $D_{L}$. Hence, the error $e_{\mathrm{PHss}}$ is minimized by selecting $D_{L}$ appropriately.

(2) The RMS error between the fitted and the experimental pressure responses immediately after the heater is turned on or off, indicated by $e_{\text {PHin }}$ in figure 6 , has been observed to depend primarily on $\tau_{a}$. Hence, the error $e_{\mathrm{PHin}}$ is minimized by selecting $\tau_{a}$ appropriately.

(3) The difference between the maximum pressure values for the fitted and the experimental pressure responses, indicated by $e_{\mathrm{PHmx}}$ in figure 6 , has been observed to depend primarily on $V_{\mathrm{crr}}$. Hence, the error $e_{\mathrm{PHmx}}$ is minimized by selecting $V_{\text {crr }}$ appropriately.

(4) The fitted parameter $f$ is used to minimize the total RMS error, $e_{\mathrm{RMS}}$, between the fitted and the experimental pressure responses (figure 6). Hence, the error $e_{\mathrm{RMS}}$ is minimized by selecting $f$ appropriately.

Figure 7 shows the flowchart for the fitted model; further details are available in [Gup10]. Thus, the fitted model provides an estimate for the fitted parameters $V_{\mathrm{crr}}, D_{L}, \tau_{a}$ and $f$, such that the RMS error between the experimentally measured and the modeled pressure in the hot chamber is minimized. The tolerances $\varepsilon_{1}, \varepsilon_{2}, \varepsilon_{3}$ and $\varepsilon$ may vary from one iteration to the next.

\section{Experimental results}

As noted previously, four types of ceramics were evaluated in this effort.

(a) A 15 bar microporous ceramic (denoted 15PC). This is a clay-based porous ceramic (Soil Moisture Corp., CA) with air entry value of 15 bar. The air entry value is the pressure at which air will break through a wetted pore channel.

(b) A 5 bar microporous ceramic (denoted 05PC). This is another clay-based porous ceramic from the same company with air entry value of 5 bar.

(c) A porous glass, VYCOR (denoted VYPG), from Corning Inc.

(d) A naturally occurring zeolite, clinoptilolite (denoted ZEO).

\subsection{Characterization of microporous ceramics}

The ceramics 15PC, 05PC and VYPG have bulk porosity of $32 \%, 31 \%$ and $28 \%$, respectively. (Although these are commercially available ceramics with known bulk porosity $\left(f_{p}\right)$, no reliable data for the pore size distribution are available.) In contrast, clinoptilolite has an average pore diameter $D_{\mathrm{NP}}(=2 a)$ of $0.45 \mathrm{~nm}$ and bulk porosity $f_{p}$ of $34 \%$ [Li05]. However, the porosity data are not reliable because naturally occurring zeolite samples may have varying levels of pore blockage and other defects. In addition to the structural parameters $a$ and $f_{p}$, a complete analysis of the gas flow requires the knowledge of the leak aperture diameter, $D_{L}$.

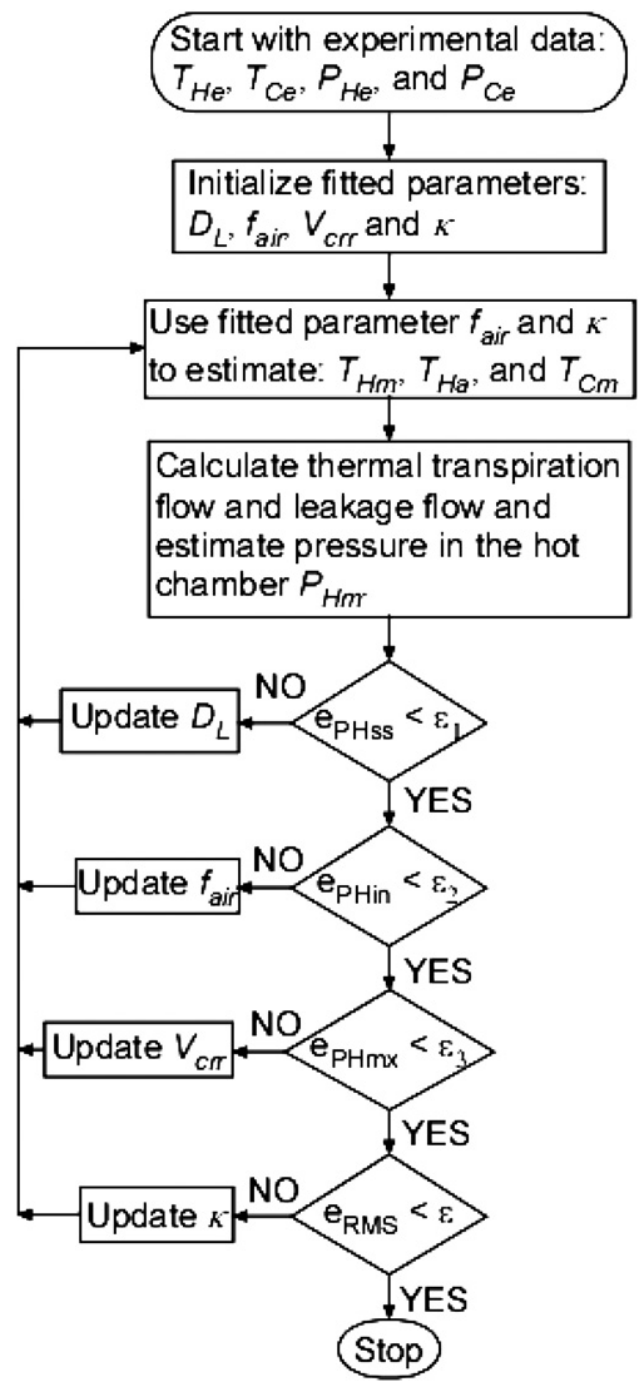

Figure 7. The flowchart for key steps involved in the fitted model.

This section summarizes a technique for using experimentally measured flow characteristics and one of the (known) structural parameters $\left(a\right.$ or $\left.f_{P}\right)$ to estimate the other two (unknown) structural parameters. Two sets of experimental measurements are needed: (a) the isothermal pressure-driven gas flow characteristic of the sample ceramic (e.g. figure 8); (b) the variation in the gas flow generated by a SSKP using that ceramic (e.g. figure 9).

The measured variation of the flow rate with pressure head is extrapolated to estimate the gas flow, $Q_{\mathrm{mxE}}$, that the pump can generate with zero pressure head at its outlet (figure 9). The flow characteristics also indicate the maximum pressure head, $P_{\mathrm{mxE}}$, that the pump can generate. Because a Knudsen pump operating at a near-zero pressure head will also experience negligible leakage flow, $Q_{\mathrm{mxE}}$ will have almost no contribution from leakage flow. Hence, $Q_{\mathrm{mxE}}$ represents the thermal transpiration-driven gas flow across the ceramic without any leakage flow across the ceramic. Knowing $Q_{\mathrm{mxE}}$ and one of the structural parameters, $a$ or $f_{p}$, the first step is to use equation (1) to get an initial estimate of the second (unknown) structural parameter ( $f_{p}$ or $a$, respectively). In the second step, the parameters $a$ and $f_{P}$ are used to calculate the 


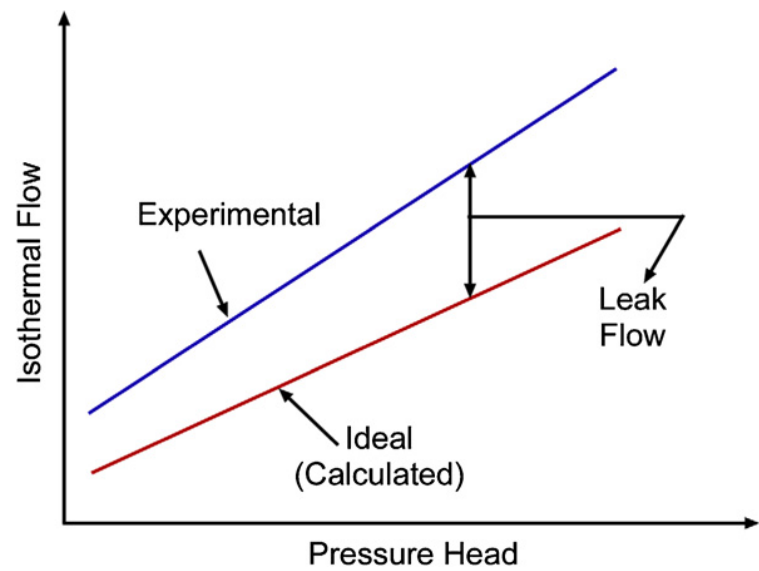

Figure 8. A typical variation in the isothermal pressure-driven gas flow generated across a ceramic with the externally applied pressure head.

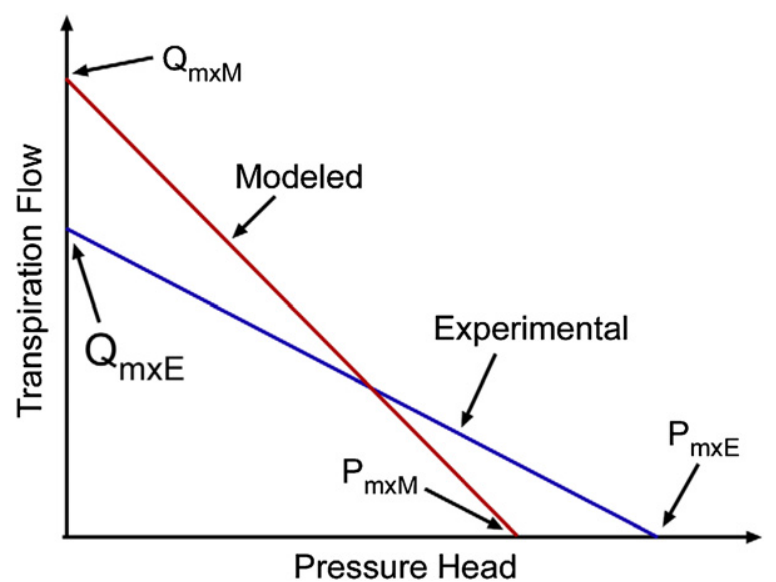

Figure 9. A typical variation in the thermal transpiration-driven gas flow rate generated across a Knudsen pump with pressure head at its outlet (or inlet).

ideal isothermal pressure-driven gas flow expected across the ceramic (shown in figure 8). (The ideal case corresponds to $D_{L}=0$.) The difference between the experimentally measured flow and the ideal flow provides an estimate of the leakage flow across the ceramic disk for a particular pressure head, which is used to estimate the leak aperture diameter $D_{L}$ (equation (3)). In the third step, $a, D_{L}$ and $f_{p}$ are used to model the thermal transpiration-driven gas flow generated by the Knudsen pump (shown in figure 9). This modeled flow characteristic provides an estimate of the maximum pressure head, $P_{\mathrm{mxM}}$, and the maximum flow rate, $Q_{\mathrm{mxM}}$, expected from the device for a given set of parameters- $a, f_{P}$ and $D_{L}$. Steps 1-3 described above are iterated and the unknown parameter, $a$ or $f_{p}$, is finetuned further such that the errors are symmetric at the axis intercepts:

$$
\left|\frac{Q_{\mathrm{mxE}}-Q_{\mathrm{mxM}}}{Q_{\mathrm{mxE}}}\right| \approx\left|\frac{P_{\mathrm{mxE}}-P_{\mathrm{mxM}}}{P_{\mathrm{mxE}}}\right| .
$$

Each iteration yields a corresponding value for $D_{L}$. The parameters $Q_{\mathrm{mxM}}$ and $P_{\mathrm{mxM}}$ may deviate significantly from $Q_{\mathrm{mxE}}$ and $P_{\mathrm{mxE}}$, respectively, because $Q_{\mathrm{mxM}}$ and $P_{\mathrm{mxM}}$ do not
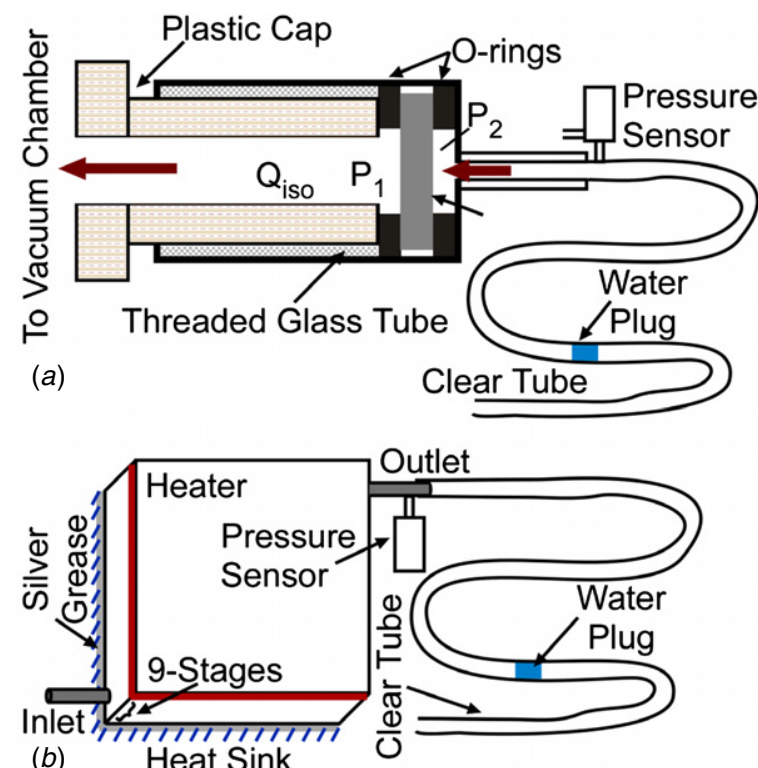

Figure 10. Test set-ups for $(a)$ isothermal pressure-driven gas flow characterization of microporous ceramics; and $(b)$ thermal transpiration-driven gas flow characterization of a Knudsen pump.

account for all the non-idealities present in the system (detailed in section 3).

\subsection{Test set-up}

Two experimental set-ups were used. The first set-up was for the characterization of isothermal pressure-driven gas flow in the porous ceramic transpiration elements (figure 10(a)). In each case, a $25 \mathrm{~mm}$ diameter ceramic sample was sandwiched between a threaded glass tube and a plastic cap. 'O'-rings were used to seal the ceramic disk between the tube and the cap. The cap was connected to a vacuum chamber, which was used to apply a controlled differential pressure across the ceramic element. The other end of the glass tube was connected to a clear Tygon tube that contained a water plug to visualize and quantify the gas flow through the ceramic element.

The second test set-up was used to study the performance characteristics of the Knudsen pumps (figure 10(b)). Each device was tested in two different operation modes: pressure mode and flow mode. While operating in the pressure mode, the pump outlet was sealed, a pressure sensor (model MPXM2053D, Freescale Semiconductor, AZ) was attached at the sealed outlet and the inlet was open to the ambient, i.e. the inlet was at atmospheric pressure. This mode was used to quantify the maximum limiting pressure head against which the device could pump gas. While operating in the flow mode, flexible tubing (ID $0.79 \mathrm{~mm}$ ) with water plugs, and a pressure sensor were connected to the outlet of the pump through a T-joint; the inlet was open to ambient. This mode was used to characterize the variation, with applied pressure head, in the air flow generated by the pump at the outlet for different input power levels. Thermocouples, attached to the brass top and the brass base, were used to record the applied temperature bias across the ceramic element. The voltage output from the two thermocouples and the pressure sensor were read into 


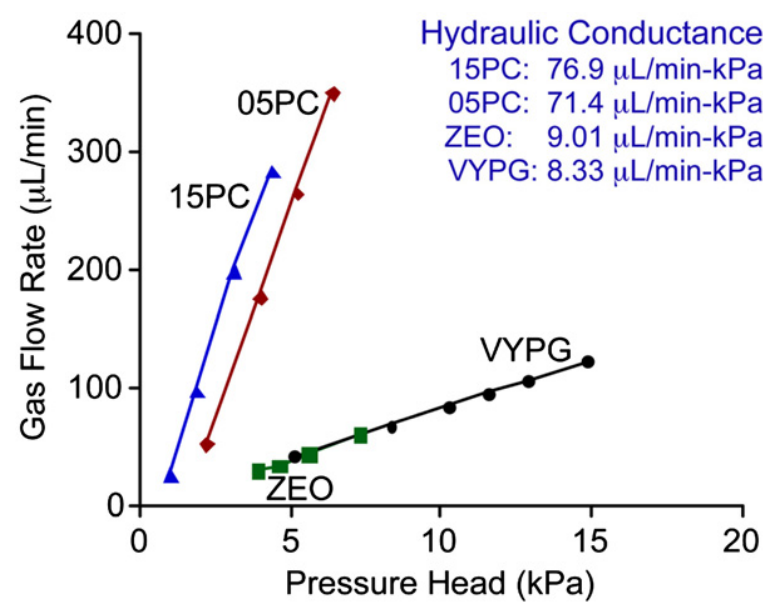

Figure 11. Isothermal pressure-driven gas flow characteristics of various microporous ceramic disks. Variation in the experimentally measured isothermal pressure-driven gas flow rates across $25 \mathrm{~mm}$ diameter and $\approx 2.7 \mathrm{~mm}$ thick microporous ceramic disks with externally applied pressure head was used to estimate their hydraulic conductance.

HP34401A multimeters, which were connected to a personal computer through a data transfer cable (National Instruments GPIB-USB-HS). A Labview ${ }^{\mathrm{TM}}$ interface program was used to record the temporal variation of the voltage outputs.

\subsection{Steady-state characterization}

4.3.1. Isothermal Poiseuille gas flow. Figure 11 illustrates the isothermal pressure-driven gas flow characteristics across porous disks of $\approx 25 \mathrm{~mm}$ diameter and $\approx 2.7 \mathrm{~mm}$ thickness. The variation of the gas flow rate across each ceramic disc with the externally applied pressure head was used to estimate the hydraulic conductance. The ceramic 15PC had highest conductance $\left(\approx 76.9 \mu \mathrm{L} \min ^{-1} \mathrm{kPa}^{-1}\right)$ followed closely by $05 \mathrm{PC}\left(\approx 71.4 \mu \mathrm{L} \mathrm{min}^{-1} \mathrm{kPa}^{-1}\right)$. The ZEO and VYPG samples had about an order of magnitude lower hydraulic conductance $\left(\approx 9 \mu \mathrm{L} \mathrm{min}{ }^{-1} \mathrm{kPa}^{-1}\right)$.

A procedure to estimate the structural parameters of the bulk microporous ceramics is described in section 4.1. The experimentally measured pressure-driven Poiseuille flow through the ceramic transpiration element has two components-the flow through the micropores (equation (1)) and that through leakage apertures (equation (3)). For structurally perfect porous ceramics, there is no leakage flow and the expected idealized gas flow rate is given by equation (1). The deviation of the experimentally measured gas flow from the ideal case provides an estimate of $D_{L}$ for the bulk microporous ceramic disks.

4.3.2. Thermal transpiration-SSKP. Figure 12 shows the relative performance of SSKPs based on various microporous ceramics. While operating in pressure mode, 15PC-, 05PCand ZEO-SSKP resulted in almost identical pressure ratios, $P_{H} / P_{C}$, for a given temperature ratio, $T_{H} / T_{C}$ (figure $12(a)$ ). However, the VYPG-SSKP resulted in a significantly higher pressure ratio than the 15PC-, 05PC- and ZEO-SSKP. The
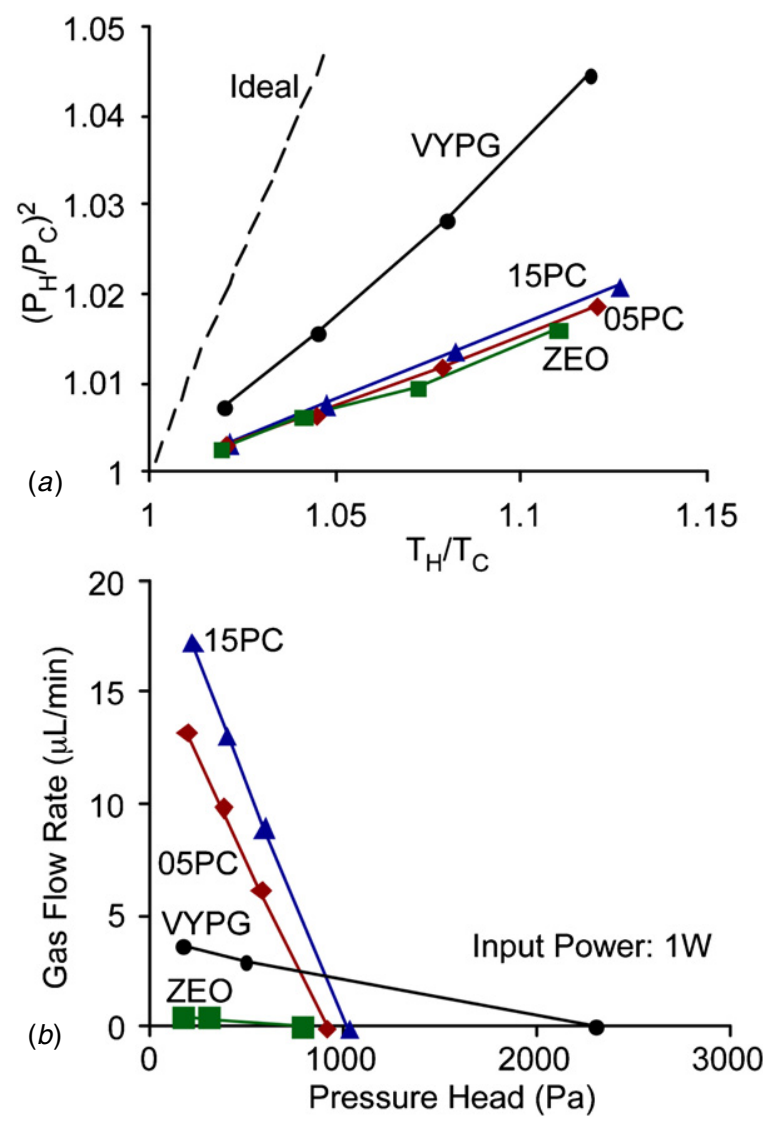

Figure 12. Typical performance characteristics of SSKPs based on various porous ceramics: clay-based 15 bar porous ceramic (15PC), clay-based 5 bar microporous ceramic (05PC), VYCOR porous glass (VYPG) and zeolite (ZEO). (a) Variation in the square of pressure ratio $P_{H} / P_{C}$ with applied temperature ratio $T_{H} / T_{C}$ for SSKPs. (b) The gas flow rate generated by single-stage pumps, based on the four ceramics for different applied pressure head at the outlet.

plot also identifies the idealized limit for the performance of a Knudsen pump. The idealized limit corresponds to the case for which (a) the ceramic transpiration element has no structural defects that provide a leakage path; (b) there exists no thermal contact resistance at the interface between the ceramic disk and the brass elements; and (c) the upper and the lower surfaces of the ceramic transpiration element are at uniform temperature.

Flow mode testing of these single-stage pumps indicated that the maximum pressure head $\left(P_{\mathrm{mxE}}\right)$ generated by the VYPG-SSKP was $>2 \times$ greater than that of any other SSKP. However, in the absence of a pressure load, the VYPG-SSKP had $\approx 5 \times$ smaller gas flow generation capabilities $\left(Q_{\mathrm{mxE}}\right)$ as compared to the best performing 15PC-SSKP (figure 12(b)). The gas flow generated by each of these pumps decreased linearly with increasing pressure head at the outlet.

As described in section 4.1, the flow characteristics illustrated in figures 11 and 12(b) were used to estimate the unknown structural parameters of the ceramics. Table 2 summarizes the average value for the three structural parameters for the ceramics. Note that the encircled parameter values were already known, while the remaining parameters were estimated based on the procedure discussed in section 4.1. 
Table 2. Summary of micropore diameter $D_{\mathrm{NP}}$, bulk porosity $f_{p}$ and leak aperture diameter $d_{L}$ of various microporous ceramics. The encircled parameter values were already known, while the remaining parameters were estimated based on the procedure discussed in section 4.1 .

\begin{tabular}{|c|c|c|c|}
\hline Material & Pore Diameter & Percent Porosity & Leak Aperture \\
\hline Units & $\mathrm{nm}$ & $\%$ & $\mu \mathrm{m}$ \\
\hline Symbol & $D_{N P}$ & $f_{p}$ & $d_{L}$ \\
\hline $15 \mathrm{PC}$ & $1.23_{+0.66}^{-0.26}$ & 32 & $21.1-22.5$ \\
\hline 05PC & $1.08_{+0.52}^{-0.22}$ & 31 & $21.0-22.2$ \\
\hline ZEO & 0.45 & $5.2_{+4.7}^{-1.8}$ & $14.4-14.9$ \\
\hline VYPG & $0.47_{+0.01}^{-0.02}$ & 28 & $13.5-13.7$ \\
\hline
\end{tabular}

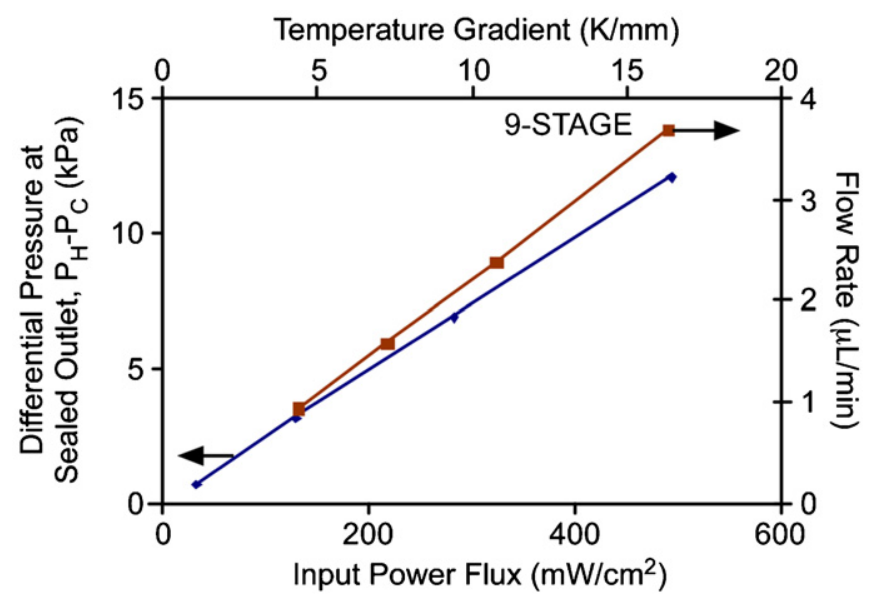

Figure 13. Steady-state performance characteristics of the 15PC, nine-stage, Knudsen pump (i.e. MSKP). The maximum (steady-state) pressure head generated at the sealed outlet increases linearly with the input power density to the device. Similarly, the gas flow rate measured at the outlet against a pressure head of $\approx 160 \mathrm{~Pa}$ increases linearly with the input power. The top axis indicates the temperature gradient across the thickness of the microporous ceramic corresponding to various input power densities to the device.

4.3.3. Thermal transpiration-MSKP. Based on the performance characteristics of various SSKPs, discussed in section 4.3.2, the ceramic 15PC was identified as the preferred material for the MSKP. A MSKP using this ceramic resulted in a maximum (steady-state) differential pressure, $P_{H}-P_{C}$, of $\approx 12 \mathrm{kPa}$ at the outlet for a temperature gradient of $\approx 16.5 \mathrm{~K} \mathrm{~mm}^{-1}$ across the microporous ceramics (figure 13). The pressure rise at the sealed outlet was directly proportional to the temperature gradient applied across the porous transpiration element, which, in-turn, was linearly dependent on the input power density to the device.

The variation in the gas flow rate generated by the MSKP decreased linearly with the applied pressure head at its outlet (figure 14). The flow also scaled down linearly with the power density applied to the device. A sustained temperature gradient of $\approx 16.5 \mathrm{~K} \mathrm{~mm}^{-1}$ across the $15 \mathrm{PC}$ ceramic disks in a MSKP required an input power density of $525 \mathrm{~mW} \mathrm{~cm}^{-2}$. A temperature gradient of $16.5 \mathrm{~K} \mathrm{~mm}^{-1}$ resulted in a maximum gas flow rate of $\approx 3.7 \mu \mathrm{L} \mathrm{min}{ }^{-1}$ against a pressure head of $\approx 160 \mathrm{~Pa}$

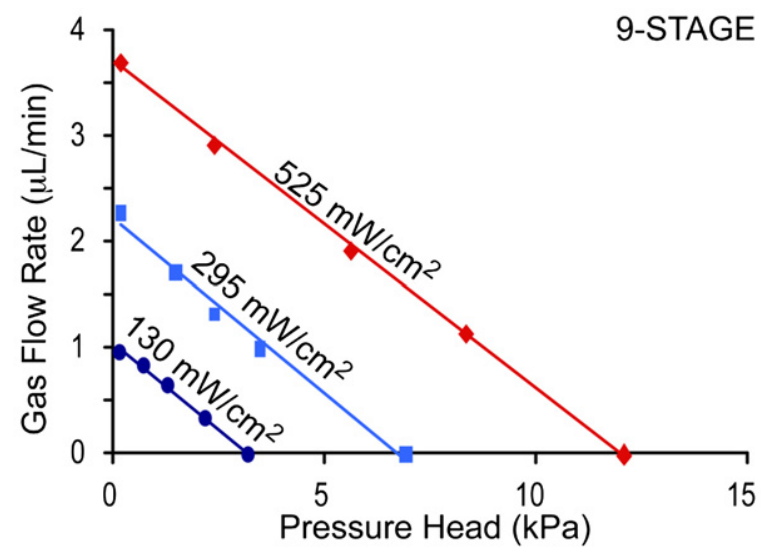

Figure 14. Gas flow characteristics of the 15PC, nine-stage, Knudsen pump (i.e. MSKP). The gas flow rate decreases linearly with increasing pressure head applied at the outlet.

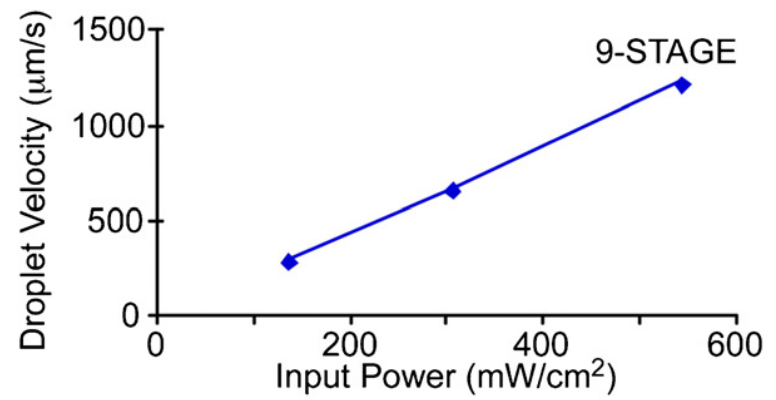

Figure 15. Velocity at which the 15PC, nine-stage, Knudsen pump (i.e. MSKP) could push a water droplet through a $250 \mu \mathrm{m}$ ID fluorinated ethylene propylene capillary for different input power densities.

The fluid manipulation capability of the MSKP for potential application to droplet manipulation in microfluidic assays is shown in figure 15. For an input power density of $525 \mathrm{~mW} \mathrm{~cm}^{-2}$, the device could maneuver a water droplet plug at speeds in excess of $1.2 \mathrm{~mm} \mathrm{~s}^{-1}$ through $250 \mu \mathrm{m}$ ID fluorinated ethylene propylene (FEP) tubing, connected to its outlet. The pressure head required to push the droplet was $925 \mathrm{~Pa}$. The plot suggests that the droplet speed is directly proportional to the input power to the device. 


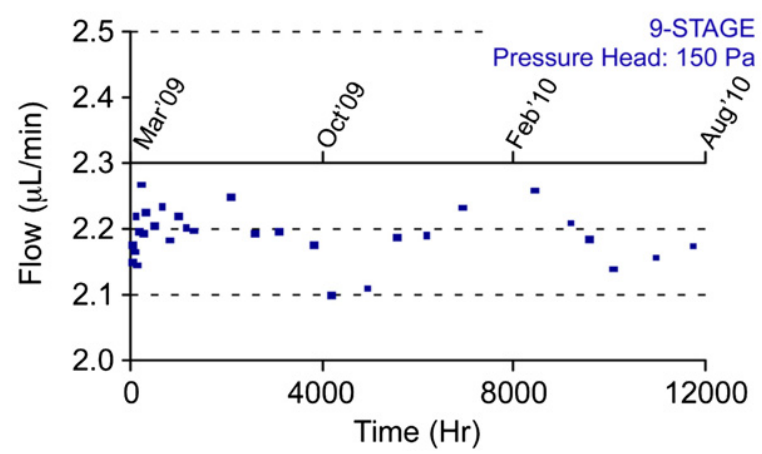

Figure 16. The variation in gas flow rate with time during a continuous $11750 \mathrm{~h}$ operation of the 15PC, nine-stage, Knudsen pump (i.e. MSKP). The average gas flow rate generated during this period is $2.2 \mu \mathrm{L} \mathrm{min}-1$ with a standard deviation of $0.04 \mu \mathrm{L} \mathrm{min}{ }^{-1}$.

In order to test the reliability of ceramic-based Knudsen pumps, the MSKP was operated continuously for an extended duration of time in a laboratory ambient. It operated continuously for $\approx 11750 \mathrm{~h}$ without any deterioration in its performance (figure 16). For an input power of $1.9 \mathrm{~W}$, the average gas flow generated by the MSKP during this period is $\approx 2.2 \mu \mathrm{L} \mathrm{min}-1$ with a standard deviation of $\approx 0.04 \mu \mathrm{L}$ $\min ^{-1}$. (This flow rate was measured against a pressure load of $150 \mathrm{~Pa}$.) The variation in the gas flow rate was primarily due to the variation in the ambient operating temperature of the device. Variation in ambient temperature resulted in fluctuation of the effective temperature bias across the ceramic transpiration elements, which, in-turn, resulted in the variation of the gas flow rate.

\subsection{Transient response}

4.4.1. Transient response of SSKPs. Figure 17 shows the experimentally measured transient pressure response, $P_{\mathrm{He}}-P_{\mathrm{Ce}}$, of a 15PC-SSKP at its sealed outlet, corresponding to the temperatures $T_{\mathrm{He}}$ and $T_{\mathrm{Ce}}$, measured experimentally at the hot and the cold ends of the pump, respectively. The fitted model discussed in section 3 was used to quantify the four fitted parameters that control the temporal evolution of pressure at the sealed outlet of the device. The device had an estimated leak aperture $d_{L}$ of $\approx 18.8 \mu \mathrm{m}$ while heating and $\approx 19.2 \mu \mathrm{m}$ while cooling. The initial pressure transients that occurred as soon as the heater was turned on (or off) were captured adequately by the fitted parameters $V_{\mathrm{crr}}$ and $\tau_{a}$. The corrected volume of the hot chamber $V_{\text {crr }}$ was $0.32 \mathrm{cc}$, which was $20 \%$ of the actual physical volume of the hot chamber. The thermal time constant of air $\tau_{a}$, for the period when the heater was turned on, was $\approx 494 \mathrm{~s}(\approx 5.5 \times$ the corresponding time constant for heater). In contrast, $\tau_{a}$ for the period when the heater was turned off was $\approx 568 \mathrm{~s}(\approx 8 \times$ the corresponding time constant for heater). (Anisotropy in gas flow may contribute to differences in the thermal time constants.) Finally, the model suggested that the loss in temperature bias due to the thermal contact resistance was about $49 \%$ (i.e. $f \approx 0.51$ ). Based on these fitted parameters, the modeled pressure response, $P_{\mathrm{Hm}}-P_{\mathrm{Cm}}$, could reproduce the experimentally observed pressure response, $P_{\mathrm{He}}-P_{\mathrm{Ce}}$, with a root mean square error (RMSE) of $<30 \mathrm{~Pa}$.

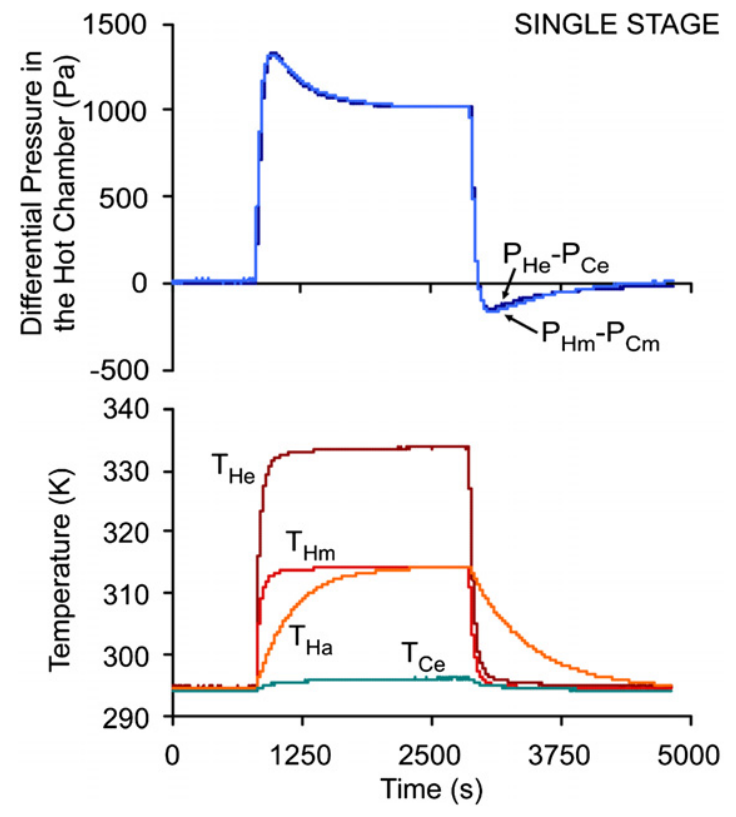

Figure 17. Variation in the experimentally measured pressure rise $P_{\mathrm{He}}-P_{\mathrm{Ce}}$ at the sealed outlet of the 15PC SSKP corresponding to the experimentally measured temperatures $T_{\mathrm{He}}$ at the hot and $T_{\mathrm{Ce}}$ at the cold ends of the microporous ceramic. $T_{\mathrm{Hm}}$ is the corrected temperature of the hot facet of the microporous ceramic, $T_{\mathrm{Ha}}$ is the modeled temperature of the air in the hot chamber and $P_{\mathrm{Hm}}-P_{\mathrm{Cm}}$ is the pressure rise at the sealed outlet-as predicted by the fitted model. The root mean square error between $P_{\mathrm{He}}-P_{\mathrm{Ce}}$ and $P_{\mathrm{Hm}}-P_{\mathrm{Cm}}<30 \mathrm{~Pa}$.

4.4.2. Transient response of MSKPs. Figure 18 shows the experimentally measured transient pressure response, $P_{\mathrm{He}}-P_{\mathrm{Ce}}$, at the sealed outlet of a 15PC-based MSKP. The corresponding temperatures measured at the hot and the cold facets of the device are indicated by $T_{\mathrm{He}}$ and $T_{\mathrm{Ce}}$, respectively. The temperatures were measured at the top and the bottom of the fifth stage, whereas the pressure $P_{\mathrm{He}}$ was measured at the outlet of the ninth stage and $P_{\mathrm{Ce}}$ was measured at the inlet of the first stage.

The MSKP model is comprised of nine interlinked fitted models, one for each of the nine stages, such that the pressure at the outlet of one stage is reflected at the inlet of the next stage. Table 3 summarizes the values for various fitted parameters that adequately capture the temporal evolution of pressure at the sealed outlet of the device. The relative location of individual stages in the MSKP with respect to the inlet (I) and outlet $(\mathrm{O})$ are indicated by dark circles in the first row of table 3. Based on these fitted parameters, the modeled pressure response, $P_{\mathrm{Hm}}-P_{\mathrm{Cm}}$, could reproduce the experimentally observed pressure response, $P_{\mathrm{He}}-P_{\mathrm{Ce}}$, with a RMS error of $\approx 110 \mathrm{~Pa}$.

\section{Discussion}

Although the ceramic 15PC has the largest leak aperture, $d_{L}$ (table 2), of those studied in this effort, it offers the best performance amongst the ceramic materials considered. This is because it has the largest pore diameter, $D_{\mathrm{NP}}$, and the highest 
Table 3. Summary of fitted parameters for the 15PC-MSKP.

\begin{tabular}{|c|c|c|c|c|c|c|c|c|c|c|c|}
\hline $\begin{array}{c}\text { Location } \\
\text { in } 3 \times 3 \\
\text { array } \\
\text { Fitted pa- } \\
\text { rameters }\end{array}$ & Units & Heater & 808 & $808^{\circ}$ & 808 & 808 & Fifth stage & 808 & 808 & 808 & 808 \\
\hline$V_{\text {crr }}$ & $\mathrm{cm}^{3}$ & - & 0.01 & 0.01 & 0.01 & 0.01 & 0.01 & 0.01 & 0.01 & 0.01 & 0.26 \\
\hline$\tau_{a} \quad$ Heat & $\mathrm{s}$ & 90 & 126 & 126 & 126 & 126 & 126 & 126 & 126 & 126 & 207 \\
\hline Cool & $\mathrm{s}$ & 94 & 132 & 132 & 132 & 132 & 132 & 132 & 132 & 132 & 216 \\
\hline Heat & $\mu \mathrm{m}$ & - & 22 & 22 & 22 & 22 & 22 & 22 & 22 & 22 & 29 \\
\hline Cool & $\mu \mathrm{m}$ & - & 22 & 22 & 22 & 22 & 22 & 22 & 22 & 22 & 29 \\
\hline$f$ & & - & 0.88 & 0.88 & 0.88 & 0.93 & 0.93 & 0.93 & 0.88 & 0.88 & 0.88 \\
\hline
\end{tabular}



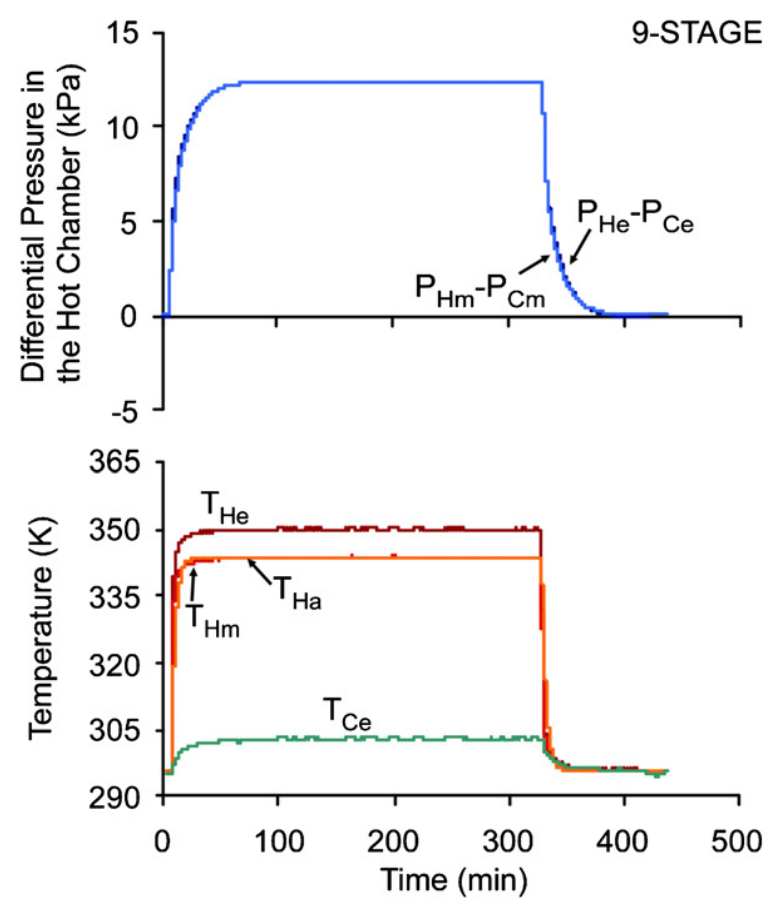

Figure 18. Variation in the experimentally measured pressure rise $P_{\mathrm{He}}-P_{\mathrm{Ce}}$ at the sealed outlet of the 15PC, nine-stage, Knudsen pump (i.e. MSKP) corresponding to the experimentally measured temperatures $T_{\mathrm{He}}$ at the hot and $T_{\mathrm{Ce}}$ at the cold ends of the microporous ceramic. $T_{\mathrm{Hm}}$ is the modeled temperature of the hot facet of the microporous ceramic, $T_{\mathrm{Ha}}$ is the corrected temperature of the air in the hot chamber and $P_{\mathrm{Hm}}-P_{\mathrm{Cm}}$ is the corresponding pressure rise at the sealed outlet-as predicted by the fitted model. The root mean square error between $P_{\mathrm{He}}-P_{\mathrm{Ce}}$ and $P_{\mathrm{Hm}}-P_{\mathrm{Cm}}$ $<110 \mathrm{~Pa}$.

porosity $f_{p}$. Hence, the effective thermal transpiration-driven gas flow generated by $15 \mathrm{PC}$, even after accounting for the leakage flow, is higher than other ceramics.

The leak aperture $d_{L}(\approx 22.2 \mu \mathrm{m})$ for the 15PC-SSKP, as estimated from the steady-state characterization (section 4.1), is reasonably close to the $d_{L}(\approx 19 \mu \mathrm{m})$ predicted by the fitted model. Similarly, for the MSKP, the fitted model suggests that the stages $1-8$ should have $d_{L} \approx 22 \mu \mathrm{m}$, which is in good agreement with the $d_{L}$ for 15PC estimated using steadystate characterization. However, $d_{L}$ for the ninth stage, as predicted by the fitted model, is larger $(\approx 29 \mu \mathrm{m})$ than that for the remaining stages, potentially because of additional leakage across various joints/fitting at the outlet of the device.

Based on the experimental characterization of various ceramics, $15 \mathrm{PC}$ was identified as a favorable ceramic for multistage Knudsen pumping. Although the VYPG-SSKP results in $\approx 2 \times$ greater pressure head than the $15 \mathrm{PC}$-SSKP, the maximum gas flow rate generated by the 15PC-SSKP is $>5 \times$ greater than the maximum gas flow rate generated by the VYPG-SSKP (figure 12(b)). The 15PC-SSKP also offered greater flow than the ZEO-SSKP and the 05PC-SSKP.

The transient variation of the differential pressure in the hot chamber of the 15PC-SSKP does not follow the same general trend reported in earlier studies [You05, Han07, Han09] which appear similar to an overdamped transient response (figure 17). Two possible reasons for this deviation are that for the device presented here, the volume of the hot chamber is significantly smaller and the heating rate is potentially larger. Both of these contribute to a rapid increase in the chamber pressure. The volume of the hot chamber depends on the geometry of the device, whereas the rate of heating depends on the thermal mass of the device and the power delivered to the heater. For the experimental results presented in figure 17, the initial pressure rise due to the thermal expansion of the air in the hot chamber dominates the pressure release due to the outflow of air through the leak aperture. This leads to a spike in the measured pressure; however, with time, the excess gas molecules leak out of the hot chamber, allowing the pressure in the hot chamber to settle to a steady-state value. At steady state, the pressure in the hot chamber is dynamically balanced by the thermal transpiration flow into the hot chamber and (Poiseuille) leakage flow, through the leak aperture, out of the hot chamber.

For the 15PC-SSKP, $\tau_{a}$ for heating was observed to be smaller than $\tau_{a}$ for cooling. This is potentially because the direction of gas flow across the transpiration element (15PC) in these cases is opposite. As soon as the heater is turned on, the unheated air starts flowing from the cold side to the hot side of the transpiration element. While passing through the transpiration element, the air gets pre-heated, which favors the heating of the air in the hot chamber, thus reducing $\tau_{a}$ for heating. In contrast, as soon as the heater is turned off, the heated air in the hot chamber moves from the hot side of the transpiration element to the cold side. This does not assist the cooling of the (remaining) air in the hot chamber. Hence, $\tau_{a}$ for cooling is larger than $\tau_{a}$ for heating.

The fitted model for the 15PC-SSKP suggests that only $20 \%$ of the actual physical volume of the hot chamber contributes to $V_{\text {crr }}\left(\approx 0.32 \mathrm{~cm}^{3}\right)$. The contribution is even smaller (17\%) for the MSKP. This is potentially because the footprint of individual stages in the MSKP is significantly smaller than that in the 15PC-SSKP; hence, the volume of air closer to heater is significantly less in the MSKP than in the 15PC-SSKP. In contrast, for stages 1-8 in the MSKP, 85\% of the actual physical volume of the hot chamber constitutes $V_{\text {crr }}$. This high percentage is potentially because the hot chambers for stages 1-8 are comprised primarily of the vertical transfer ports that serve to connect adjacent stages. These transfer ports are embedded in the PEI substrate and are sealed at ends with brass caps that are located directly underneath the heater. Hence, a significant portion of the air entrapped in these transfer ports gets heated, resulting in higher percentage for $V_{\mathrm{crr}}$.

For stages $1-8$ in the MSKP, $\tau_{a}$ is $1.4 \times$ the thermal time constant for heater itself, whereas $\tau_{a}$ for the air entrapped in the ninth stage is $\approx 2.3 \times$ the thermal time constant for heater. The ninth stage has a longer time constant because it has a larger volume of air encapsulated in its hot chamber that must be heated. Similarly, $\tau_{a}$ of heating/cooling for the 15PC-SSKP is significantly larger than any of the stages in the MSKP because the 15PC-SSKP has significantly larger $V_{\mathrm{crr}}$.

The arrayed structure of the MSKP results in non-uniform thermal loss from different stages. Hence, the temperature bias across various stages is expected to be non-uniform. Moreover, 
the heater used in this work is narrower on one side, so the stages 1-3 and 7-9 are not completely covered by the heater, which contributes to the non-uniformity in temperature bias across various stages. A finite-element $\left(\mathrm{COMSOL}^{\mathrm{TM}}\right)$ model is used to estimate the relative variation in temperature bias across various stages with respect to the fifth stage. (The temperature bias across the fifth stage is used as reference because it is located at the center and is expected to have the highest temperature bias.) Subsequently, the fitted model is used to estimate the fitted parameter $f$ for the fifth stage. The parameters $f$ for remaining stages are determined by scaling down the fitted value of $f$ for the fifth stage based on the relative variation in the temperature bias across these stages, as predicted by the finite-element model. The fitted parameter $f$ is 0.88 for stages $1-3$ and $7-9$, whereas its value for stages 4-6 is 0.93 .

The model uses nominal values for the unknown parameters $\left(a\right.$ or $\left.f_{p}\right)$, which are derived from the steady-state characterization of various ceramics (table 2). The limiting values for the derived structural parameters are associated with the following cases:

$$
\left|\frac{Q_{\mathrm{mxE}}-Q_{\mathrm{mxM}}}{Q_{\mathrm{mxE}}}\right| \approx 0
$$

and

$$
\left|\frac{P_{\mathrm{mxE}}-P_{\mathrm{mxM}}}{P_{\mathrm{mxE}}}\right| \approx 0 .
$$

The values determined for the structural parameters $a$ and $f_{p}$ have significant error margins associated with them because the steady-state analysis does not account for all the nonidealities. Moreover, there could be a large standard deviation of the pore sizes and percent porosity of the ceramics (table 2). A more rigorous analysis requires the knowledge of pore size distribution, impurities in the porous ceramic, etc. Ideally, these properties should be obtained on each transpiration element without damaging the sample itself. Imaging of the transpiration elements is beyond the scope this effort.

The results suggest that the MSKP is effective in generating gas flow at pressure heads that are not possible with the SSKP [Var01, McN05, Gup08]. It is evident that with appropriate scaling, miniaturized Knudsen pumps may be useful for fluid manipulation in micro total analysis systems. The measured increment of droplet speed per unit change in input power suggests that the device can provide volumetric precision of $\approx 1 \mathrm{~nL} \min ^{-1}$ per unit $\mathrm{mW}$ change in the input power, which can be potentially useful for various microfluidic systems [Ung00, Sia03] (figure 15).

\section{Conclusion}

The 15 bar porous ceramic (15PC) from Soil Moisture and Equipment Corporation is one of the most promising ceramics for Knudsen pumps. The large pore diameter and high porosity of 15PC result in gas flow rates as high as high as $3.7 \mu \mathrm{L} \mathrm{min}^{-1}$ against a pressure head of $160 \mathrm{~Pa}$. Further, for an input power of $3.4 \mathrm{~W}$, the serially connected nine-stage structure of the MSKP, with footprint $25 \times 25 \mathrm{~mm}^{2}$, allows a pressure head as high as $12 \mathrm{kPa}$. These operating characteristics suggest the potential utility of multiple stage Knudsen pump fluid manipulation in micro total analysis systems. As a preliminary result, the nine-stage pump was able to move water drops through a $250 \mu \mathrm{m}$ ID fluorinated ethylene propylene capillary at speeds in excess of $1.2 \mathrm{~mm} \mathrm{~s}^{-1}$. Compared to other miniature pumps, the ceramic-based Knudsen pump has the potential for longevity because it lacks moving parts. As another preliminary result, the MSKP operated continuously for $\approx 11750 \mathrm{~h}$ without any observable deterioration in its performance. A semi-analytical fitted model was proposed; it uses four fitted parameters to estimate the highly nonlinear temporal evolution of the pressure at the sealed outlet of the SSKPs and the MSKPs. The fitted model can reproduce the experimentally measured results with a root mean square error of $<110 \mathrm{~Pa}$.

Having demonstrated the feasibility of the MSKP to meet the performance requirement of various microsystems, the fabrication process and the materials used can be refined further to optimize the efficiency of the device and to minimize the size of the device. A suitable choice of materials and fabrication steps is expected to enable batch fabrication methods for these devices.

\section{Acknowledgments}

NG acknowledges partial support by a fellowship from the Mechanical Engineering Department at the University of Michigan. YG acknowledges support through the IR/D program while working at the National Science Foundation. The study was also supported in part by the Microsystems Technology Office of the Defense Advanced Research Projects Agency (Hi-Vac program).

\section{References}

[Ale05] Alexeenko A A, Gimelshein S F, Muntz E P and Ketsdever A 2005 Modeling of thermal transpiration flows for Knudsen compressor optimization 43rd AIAA Aerospace Sciences Meeting and Exhibit_Meeting Papers pp 9419-29

[Ale06] Alexeenko A A, Gimelshein S F, Muntz E P and Ketsdever A D 2006 Kinetic modeling of temperature driven flows in short microchannels Int. J. Therm. Sci. 45 1045-51

[Cab01] Cabuz C, Herb W R, Cabuz E I and Son T L 2001 The dual diaphragm pump MEMS'01: Proc. 14th IEEE Int. Conf. on Micro Electro Mechanical Systems pp 519-22

[Cer06] Cercignani C 2006 Slow Rarefied Flows Theory and application to micro-electro-mechanical systems (Basel: Birkhäuser) pp 1-28

[Col05] Colin S 2005 Rarefaction and compressibility effects on steady and transient gas flows in microchannels Microfluid Nanofluid 1 268-79

[Dar96] Dario P, Croce N, Carrozza M C and Varallo G 1996 A fluid handling system for a chemical microanalyzer J. Micromech. Microeng. 6 95-8

[Guo09] Guo X, Singh D, Murthy J and Alexeenko A A 2009 Numerical simulation of gas-phonon coupling in thermal transpiration flows Phys. Rev. E 80 1-10 
[Gup10] Gupta N K 2010 A motionless gas micropump using thermal transpiration in bulk nanoporous materials $P h D$ Dissertation, University of Michigan

[Gup08] Gupta N K and Gianchandani Y B 2008 Thermal transpiration in Zeolites: a mechanism for motionless gas pumps Appl. Phys. Lett. 93 193511-1-3

[Gup09] Gupta N K and Gianchandani Y B 2009 A planar cascading architecture for a ceramic Knudsen micropump Transducers'09: Proc. 15th Int. Conf. on Solid-State Sensors, Actuators and Microsystems pp 2298-301

[Gup11] Gupta N K and Gianchandani Y B 2011 Thermal transpiration in mixed cellulose ester membranes: enabling miniature, motionless gas pumps Microporous Mesoporous Mater. 142 535-41

[Gup07] Gupta N K, Masters N D, Ye W and Gianchandani Y B 2007 Gas flow in nano-channels: thermal transpiration models with application to a Si-micromachined Knudsen pump Transducers'07: Proc. 14th Int. Conf. on Solid-State Sensors, Actuators and Microsystems pp 2329-32

[Han07] Han Y-L and Muntz E P 2007 Experimental investigation of micro-mesoscale Knudsen compressor performance at low pressures J. Vac. Sci. Technol. B 25 703-14

[Han09] Han Y-L and Muntz E P 2009 Investigation of temperature driven gas flow in $4 \mathrm{~nm}$ channels for applications of micro-scale compressors at above atmospheric pressure Proc. ASME Int. Mechanical Engineering Congress and Exposition vol. 3 pp 661-8

[Hob70] Hobson J P 1970 Accommodation pumping - a new principle for low pressures J. Vac. Sci. Technol. 7 351-7

[Hob00] Hobson J P and Salzman D B 2000 Review of pumping by thermal molecular pressure J. Vac. Sci. Technol. A 18 1758-65

[Kar05] Karniadakis G E, Beskok A and Aluru N 2005 Microflows and Nanoflows: Fundamentals and Simulation (New York: Springer) chapter 1

[Ken38] Kennard E 1938 Kinetic Theory of Gases (New York: McGraw-Hill) pp 327-32

[Kim07] Kim H, Astle A A, Najafi K, Bernal L P and Washabaugh P D 2007 A fully integrated high-efficiency peristaltic 18-stage gas micropump with active microvalves MEMS'07: Proc. 20th IEEE Int. Conf. on Micro Electro Mechanical Systems 131-4

[Knu09] Knudsen M 1909 Eine Revision der Gleichgewichtsbedingung der Gase. Thermische Molekularstromung Ann. Phys., Lpz. 336 205-29 (in German)

[Kos08] Kosuge S and Takata S 2008 Database for flows of binary gas mixtures through a plane microchannel Eur. $J$. Mech. B 27 444-65

[Las04] Laser D J and Santiago J G 2004 A review of micropumps J. Micromech. Microeng. 14 R35-64

[Li05] Li F, Jiang Y, Yu L, Hou T and Sun S 2005 Surface effect of natural zeolite (clinoptilolite) on the photocatalytic activity of $\mathrm{TiO}_{2}$ Appl. Surf. Sci. 252 1410-6

[Loe34] Loeb L 1934 The Kinetic Theory of Gases (New York: McGraw-Hill) pp 355-9
[Max79] Maxwell J C 1879 On stresses in rarefied gases arising from inequalities of temperature Philos. Trans. R. Soc. London 170 231-56

[McN05] McNamara S and Gianchandani Y B 2005 On-chip vacuum generated by a micromachined Knudsen pump J. Microelectromech. Syst. 14 741-6

[Mun02] Muntz E P, Sone Y, Aoki K, Vargo S and Young M 2002 Performance analysis and optimization considerations for a Knudsen compressor in transitional flow J. Vac. Sci. Technol. A 20 214-24

[Ngu02] Nguyen N-T, Huang X and Chuan T K 2002 MEMS-micropumps: a review Trans. ASME J. Fluids Engineering 124 384-92

[Pha10] Pharas K and McNamara S 2010 Knudsen pump driven by a thermoelectric material J. Micromech. Microeng. 20 125032-8

[Rey79] Reynolds O 1879 On certain dimensional properties of matter in the gaseous state Phil. Trans. R. Soc. Lond. $170727-845$

[Sch02] Schabmueller C G J, Koch M, Mokhtari M E, Evans A G R, Brunnschweiler A and Sehr H 2002 Self-aligning gas/liquid micropump J. Micromech. Microeng. 12 420-4

[Sch94] Schomburg W K, Vollmer J, Bustgens B, Fahrenberg J, Hein H and Menz W 1994 Microfluidic components in LIGA technique J. Micromech. Microeng. 4 186-91

[Sha74] Shakov E M 1974 Method of Investigation of Rarefied Gas Flows (Moscow: Nauka) (in Russian)

[Sha97] Sharipov F 1997 Rarefied gas glow through a long tube at arbitrary pressure and temperature drop J. Vac. Sci. Technol. A 15 2434-6

[Sha98] Sharipov F and Seleznev V 1998 Data on internal rarefied gas flows J. Phys. Chem. Ref. Data 27 657-706

[Sia03] Sia S K and Whitesides G M 2003 Microfluidic devices fabricated in poly(dimethylsiloxane) for biological studies Electrophoresis 24 3563-76

[Ste93] Stemme E and Stemme G 1993 A valveless diffuser/nozzle-based fluid pump Sensors Actuators A 39 159-67

[Tra74] Tracey D H 1974 Thermomolecular pumping effect J. Phys. E: Sci. Instrum. 7 533-6

[Tsa07] Tsai N-C and Sue C-Y 2007 Review of MEMS based drug delivery and dosing systems Sensors Actuators A 134 555-64

[Ung00] Unger M A, Chou H-P, Thorsen T, Scherer A and Quake S R 2000 Monolithic microfabricated valves and pumps by multilayer soft lithography Science 288 113-6

[Var96] Vargo S E and Muntz E P A simple micromechanical compressor and vacuum pump for flow control and other distributed applications 34th Aerospace Sciences Meeting and Exhibit (Reno, NV, January 1996)

[Var01] Vargo S E and Muntz E P 2001 Initial results from the first MEMS fabricated thermal transpiration-driven vacuum pump AIP Conf. Proc. vol 585 pp 502-9

[You05] Young M, Han Y L, Muntz E P and Shiflett G 2005 Characterization and optimization of a radiantly driven multi-stage Knudsen compressor AIP Conf. Proc. vol 762 pp 174-9 